\title{
Publisher Correction: Effector-triggered immunity and pathogen sensing in metazoans
}

Natasha Lopes Fischer, Nawar Naseer, Sunny Shin (D) and Igor E. Brodsky (iD

Correction to: Nature Microbiology https://doi.org/10.1038/s41564-019-0623-2, published online 19 December 2019.

In this Review Article, a different panel b for the figure in Box 1 had been provided, but owing to technical issues during the production process it was mistakenly not used. The panel has now been updated to the new version.

Original

b

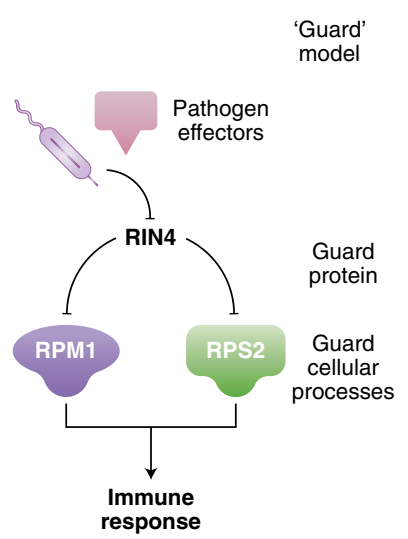

Corrected

b

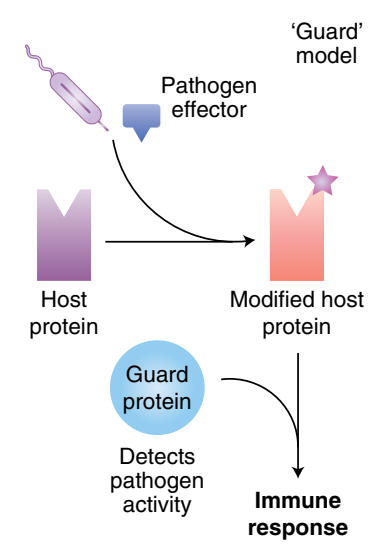

Box 1 figure | Panel b original and corrected.

Published online: 10 February 2020

https://doi.org/10.1038/s41564-020-0682-4

() Springer Nature Limited 2020 